\title{
Identification of differentially expressed genes using microarray analysis and COL6A1 induction of bone metastasis in non-small cell lung cancer
}

\author{
NAN LI ${ }^{1}$, MING LIU ${ }^{1}$, XIAOHUI CAO ${ }^{1}$, WEI LI ${ }^{1}$, YUNFANG LI ${ }^{1}$ and ZONGMAO ZHAO ${ }^{2}$ \\ ${ }^{1}$ Department of Radiotherapy and Oncology, The Third Hospital of Hebei Medical University, Shijiazhuang, Hebei 050051; \\ ${ }^{2}$ Department of Neurosurgery, The Second Hospital of Hebei Medical University, Shijiazhuang, Hebei 050000, P.R. China
}

Received December 8, 2020; Accepted June 16, 2021

DOI: 10.3892/ol.2021.12954

\begin{abstract}
Non-small cell lung cancer (NSCLC) is a major cause of cancer-associated mortality worldwide, and bone metastasis is the most prevalent event observed in patients with advanced NSCLC. However, the pathogenesis of bone metastases has not been fully elucidated. In the present study, differentially expressed genes (DEGs) were identified by gene expression microarray analysis of NSCLC tissue samples with or without bone metastases. Subsequently, collagen type 6A1 (COL6A1) was chosen as the target gene through Ingenuity Pathway Analysis and reverse transcription-quantitative (RT-q) PCR validation of the top eight DEGs. COL6A1 was overexpressed or knocked down, and the proliferation and invasion of NSCLC cells was assessed using Cell Counting Kit-8, colony formation and Transwell invasion assays. Additionally, the osteogenic capacity of HOB and hES-MP 002.5 cells was assessed using RT-qPCR, western blotting, Alizarin Red and alkaline phosphatase staining. A total of 364 DEGs were identified in NSCLC tissues with bone metastases compared with NSCLC tissues without bone metastases, including 140 upregulated and 224 downregulated genes. Gene Ontology analysis results demonstrated that the upregulated and downregulated genes were primarily enriched in 'cellular process', 'metabolic process' and 'biological regulation'. Kyoto Encyclopedia of Genes and Genomes pathway enrichment analysis revealed that the upregulated genes were primarily enriched in "cysteine
\end{abstract}

Correspondence to: Dr Zongmao Zhao, Department of Neurosurgery, The Second Hospital of Hebei Medical University, 215 West Heping Road, Xin Hua, Shijiazhuang, Hebei 050000, P.R. China

E-mail: zzm692017@sina.com

Abbreviations: NSCLC, non-small cell lung cancer; DEGs, differentially expressed genes; GO, Gene Ontology; KEGG, Kyoto Encyclopedia of Genes and Genomes; IPA, Ingenuity Pathway Analysis; COL6A1, collagen type 6A1

Key words: NSCLC, bone metastasis, gene microarray, COL6A1 and methionine metabolism', 'oxidative phosphorylation' and 'ribosome', whereas the downregulated genes were primarily enriched in the 'transcriptional misregulation in cancer', 'ribosome' and 'mitophagy-animal' pathways. COL6A1 was highly expressed in NSCLC tissue samples with bone metastases. Functionally, COL6A1 overexpression induced the proliferation and invasion of HARA cells, and its knockdown inhibited the proliferation and invasion of HARA-B4 cells. Finally, it was demonstrated that HOB and hES-MP 002.5 cells exhibited osteogenic capacity, and overexpression of COL6A1 in HARA cells increased the adhesion of these cells to the osteoblasts, whereas knockdown of COL6A1 in HARA-B4 cells reduced their adhesive ability. In conclusion, COL6A1 may serve as a potential diagnostic marker and therapeutic target for bone metastasis in NSCLC.

\section{Introduction}

Non-small cell lung cancer (NSCLC) is one of the most common causes of cancer-associated mortality, affecting $\sim 1.5$ million individuals annually worldwide $(1,2)$. Notable progress has been made in the treatment of patients with NSCLC, while the 5 -year survival rate is $<30 \%$, and thus, it remains a key challenge to public health (3). The poor prognosis of patients with NSCLC is generally attributed to a lack of effective treatments for advanced-stage cancer and metastases (4). Notably, the bone is the preferred site of metastasis from NSCLC due to its abundant blood flow and high expression levels of adhesion molecules on tumor cells $(5,6)$. Clinically, bone metastases often manifest in patients with malignant tumors, and are observed in $14-40 \%$ of patients with advanced-stage NSCLC $(4,7,8)$. Furthermore, bone metastases in patients with NSCLC often result in skeletal-associated morbidities, such as debilitating pain, fracture and spinal compression, which contribute to a poor prognosis and a low survival rate (9). Thus, early detection of bone metastasis is crucial for improving the clinical management of patients with advanced stage NSCLC. However, only a small proportion of cases of bone metastasis are accurately diagnosed, as the underlying molecular mechanisms are poorly understood (10).

NSCLC metastasis to the bone is a multifaceted biological process that involves several genes and signaling pathways, such 
as the Wnt/ $\beta$-catenin pathway (11), MAPK/ERK pathway (12) and p53 pathway (13). A clearer understanding of the key roles of these genes and signaling pathways in NSCLC bone metastasis is critical for identifying novel diagnostic markers or therapeutic targets. Advances in bioinformatics analysis in recent years have led to new approaches for disease therapy and diagnosis. Microarray analysis has increasingly become a promising tool for characterizing the molecular mechanisms of several types of cancer (14). In addition, determination of gene expression profiles combined with bioinformatics analysis have revealed numerous underlying molecular mechanisms implicated in the development of $\operatorname{NSCLC}(15,16)$.

The present study aimed to use high-throughput transcriptome expression microarray analysis technology to identify the differentially expressed genes (DEGs) between NSCLC tissue samples with or without bone metastases. Furthermore, enriched functional categories were analyzed to reveal the altered signaling pathways between the two groups. Finally, the expression levels of collagen family collagen 6A1 (COL6A1) at the mRNA and protein levels were determined in order to determine whether COL6A1 may serve as a potential diagnostic marker or therapeutic target for patients with NSCLC with bone metastases.

\section{Materials and methods}

Patients and sample collection. A total of 17 squamous cell carcinoma including 13 bone metastasis patients (age range, 41-76 years; median age, 56 years) and 23 adenocarcinoma including 6 bone metastasis patients (age range, 32-71 years; median age, 53 years) tissues were collected through resection at The Third Hospital of Hebei Medical University (Shijiazhuang, China) between February and September 2019. Normal tissues in this study were the paired adjacent tissue samples ( $2 \mathrm{~cm}$ from the lesion). None of the patients had received radiotherapy or chemotherapy prior to surgery (resection). Samples were immediately frozen in liquid nitrogen and stored at $-80^{\circ} \mathrm{C}$ further use. The study protocol was approved by the Ethics Committee of the Third Hospital of Hebei Medical University (approval no. 2019-027-1), and all patients provided written informed consent.

RNA extraction and purification. Total RNA was extracted and purified using an RNeasy mini kit (cat. no. 74106; Qiagen $\mathrm{GmbH}$ ) according to the manufacturer's protocol, and the RNA integrity number (RIN) was assessed to determine the quality of the RNA using an Agilent Bioanalyzer 2100 (Agilent Technologies, Inc.). RNA samples with a RIN value of 7.0 or $28 \mathrm{~s} / 18 \mathrm{~s} \geq 0.7$ were used for subsequent analysis.

RNA amplification and labeling. Total RNA was amplified and labeled using a Low Input Quick Amp Labeling kit, One-Color (cat. no. 5190-2305; Agilent Technologies, Inc.) according to the manufacturer's protocol. Labeled complementary (c) RNA was purified using an RNeasy mini kit (cat. no. 74106; Qiagen $\mathrm{GmbH}$ ).

Microarray hybridization analysis. Each slide of labeled cDNA was hybridized with $1.65 \mu \mathrm{g}$ Cy3-labeled cRNA using the Gene Expression Hybridization kit (cat. no. 5188-5242;
Agilent Technologies, Inc.) and a hybridization oven (cat. no. G2545A; Agilent Technologies, Inc.). Following a 17-h hybridization at $42^{\circ} \mathrm{C}$, the slides were washed in staining dishes (Thermo Fisher Scientific, Inc.) using a Gene Expression Wash Buffer kit (cat. no. 5188-5327; Agilent Technologies, Inc.).

Signal detection and data acquisition. The slides were scanned using an Agilent Microarray Scanner (cat. no. G2565CA; Agilent Technologies, Inc.) with the default settings (dye channel, green; scan resolution, $3 \mu \mathrm{m}$; photo multiplier tube, 100\%; 20-bit scan mode). Data were extracted using Feature Extraction software (version 10.7; Agilent Technologies, Inc.). Raw data were normalized using the Quantile algorithm of the 'limma' package in R software v.2.15.0 (17). All procedures were performed as previously described $(18,19)$.

Data analysis. Raw data were subjected to quality control and preprocessing, and GeneChip Robust Multichip Average normalization hierarchical clustering analysis was used to categorize the data into two groups of different expression patterns (20). Statistical analysis of gene expression was performed using a paired Student's t-test, and gene expression was expressed as the $\log _{2}$-fold change $(\log \mathrm{FC})$. The degree of gene dispersion was determined using principal components analysis (21). DEGs were identified with the following cut-off criteria: False discovery rate-corrected P-value $<0.05$ and $\mid \log \mathrm{FCl}>2$ (using the Benjamini and Hochberg method). Functional groups and biological pathway enrichment analyses for the common DEGs were performed using Gene Ontology (GO) and Kyoto Encyclopedia of Genes and Genomes (KEGG) pathway enrichment analyses (22).

Ingenuity pathway analysis (IPA). DEGs were functionally analyzed using the IPA software version 2.3 (Qiagen Inc.), which uses computational algorithms that analyze the functional connectivity of the genes from information obtained within the IPA database to describe functional relationships amongst genes or proteins. Canonical pathway analysis was performed using IPA. Networks were ranked according to their biological relevance to the provided gene list. The P-value calculated using a Fisher's exact test was used to determine the probability.

Reverse transcription-quantitative $(R T-q) P C R$. RT-qPCR was used to verify changes in the expression levels determined by the microarray analysis. Total RNA from pulmonary tumor tissue samples with and without bone metastases were extracted using TRIzol ${ }^{\circledR}$ reagent (Invitrogen; Thermo Fisher Scientific, Inc.). The quantity and purity of RNA was assessed by measuring the absorbance at 260 and $280 \mathrm{~nm}$. A total of $1 \mu \mathrm{g}$ total RNA was used as a template for cDNA synthesis using a Reverse Transcription system kit (Takara Bio, Inc.) based on the manufacturer's instructions. The conditions for reverse transcription were as follows: $95^{\circ}$ for $30 \mathrm{sec}$ and $60^{\circ} \mathrm{C}$ for 30 mins. qPCR was performed using DNA Master SYBR $^{\circledR}$ Green (Roche Diagnostics) on ABI PRISM 7500 system (Applied Biosystems; Thermo Fisher Scientific, Inc.). The thermocycling conditions for qPCR were as follows: $95^{\circ} \mathrm{C}$ for $10 \mathrm{~min}$; followed by 40 cycles of $95^{\circ} \mathrm{C}$ for $10 \mathrm{sec}, 60^{\circ} \mathrm{C}$ for $15 \mathrm{sec}$ and $72^{\circ} \mathrm{C}$ for $10 \mathrm{sec}$. The mean cycle quantification $(\mathrm{Cq})$ 
values from triplicate analyses were normalized to the mean $\mathrm{Cq}$ values of GAPDH, and the data were analyzed using the $2^{-\Delta \Delta \mathrm{Cq}}$ method (23). The primer sequences are listed in Table I.

Western blotting. Total protein was extracted from tissue samples using RIPA lysis buffer (cat. sc-24948; Santa Cruz Biotechnology Inc.), and the protein concentration was determined using a Bradford protein assay. Total protein ( $40 \mu \mathrm{g} / \mathrm{lane})$ was loaded on a $10 \%$ SDS gel, resolved using SDS-PAGE, and transferred to a PDVF membrane (MilliporeSigma). The PVDF membranes were blocked for $1 \mathrm{~h}$ with $4 \%$ milk at room temperature and subsequently incubated at $4^{\circ} \mathrm{C}$ overnight with anti-COL6A1 (1:500; cat. no. ab151422), anti-alkaline phosphatase (ALP; 1:1,000; cat. no. ab83259) or anti-RUNX family transcription factor 2 (RUNX2; 1:1,000; cat. no. ab23981) (all Abcam) primary antibodies. After washing with $0.1 \% 1 \mathrm{X}$ Tris-buffered saline-Tween (TBST) for 3 times, the membranes were incubated with an HRP-conjugated goat anti-rabbit IgG H\&L secondary antibody $(1: 2,000$; cat. no. ab6721; Abcam) at room temperature for $2 \mathrm{~h}$ prior to detection using an ECL substrate (Beyotime Institute of Biotechnology). GAPDH (1:3,000; cat. no. ab8245; Abcam) was used as the loading control for normalization. Densitometry analysis was performed using ImageJ version $1.50 \mathrm{~b}$ (National Institutes of Health).

Immunohistochemistry (IHC) analysis. Surgically excised pulmonary tumor tissue samples (with or without bone metastases) were fixed in $4 \%$ paraformaldehyde at $4^{\circ} \mathrm{C}$ for $1 \mathrm{~h}$ and embedded in paraffin. The tissue samples were sliced into 4- $\mu \mathrm{m}$ thick slices, which then were dehydrated using xylene for $15 \mathrm{~min}$ and $100,95,90,80$ and $70 \%$ ethanol for $5 \mathrm{~min}$, and incubated in $0.01 \mathrm{M}$ sodium sulphate buffer $(\mathrm{pH}=6.0)$ at $100^{\circ} \mathrm{C}$ for $2 \mathrm{~min}$. Following washing the samples with PBS, the anti-COL6A1 primary antibody (1:100; cat. no. ab151422; Abcam) was added and incubated at $4^{\circ} \mathrm{C}$ overnight. After washing the samples with PBS, Goat Anti-Rabbit IgG H\&L (1:1,000; cat. no. ab6721; Abcam) was added and incubated for $30 \mathrm{~min}$ at $37^{\circ} \mathrm{C}$. Following staining with DAB at room temperature for $10 \mathrm{~min}$, the slides were then counterstained with hematoxylin at room temperature for $20 \mathrm{sec}$ and observed with 5 fields under a light microscope (magnification, x100).

Cell culture and osteogenic induction. A549 (cat. no. CCL-185; lung adenocarcinoma), HARA (cat. no. 80005; lung squamous cell carcinoma) and NCI-H226 (cat. no. CRL-5826; lung squamous cell carcinoma) cells were obtained from the American Type Culture Collection. HARA-B4 (cat. no. 1552; lung squamous cell carcinoma) cells were obtained from the JCRB Cell Bank. HPAEpic cells (cat. no. 3200) were obtained from ScienCell Research Laboratories, Inc.; NCI-H1395 cells (cat. no. CL-0275; lung adenocarcinoma) and M-7 cells (cat. no. CL-0539) were obtained from Procell Life Science \& Technology Co., Ltd.; HOB cells (cat. no. 406-05A) were obtained from Sigma-Aldrich; Merck KGaA; and hES-MP 002.5 cells (cat. no. Y10090) were obtained from Cellartis (24). HPAEpic, A549, HARA, NCI-H226, HARA-B4 and NCI-1395 cells were cultured in DMEM (Thermo Fisher Scientific, Inc.) with 10\% FBS (Hyclone; Cytiva). HOB, hES-MP 002.5 and M-7 cells were maintained in high-glucose DMEM (Hyclone;
Table I. Sequences of primers used in the present study.

\begin{tabular}{|c|c|c|}
\hline Gene & Sequence $\left(5^{\prime}-3^{\prime}\right)$ & $\begin{array}{c}\text { Product } \\
\text { length, } \\
\text { bp }\end{array}$ \\
\hline GAPDH & $\begin{array}{l}\text { F: TGTTCGTCATGGGTGTGAAC } \\
\text { R: ATGGCATGGACTGTGGTCAT }\end{array}$ & 154 \\
\hline ALP & $\begin{array}{l}\text { F: ACTGGGGCCTGAGATACCC } \\
\text { R: TCGTGTTGCACTGGTTAAAGC }\end{array}$ & 185 \\
\hline RUNX2 & $\begin{array}{l}\text { F: TGGTTACTGTCATGGCGGGTA } \\
\text { R: TCTCAGATCGTTGAACCTTGCTA }\end{array}$ & 101 \\
\hline COA3 & $\begin{array}{l}\text { F: CTGGATTCTAAGCGTGGAGAG } \\
\text { R: AGCTCATCTAGGAAACGCTC }\end{array}$ & 236 \\
\hline APPL1 & $\begin{array}{l}\text { F: GACAGCCCGCAGACAAG } \\
\text { R: GGTGTGTTGCTGCACTTAAT }\end{array}$ & 136 \\
\hline COL6A1 & $\begin{array}{l}\text { F: ACACCGACTGCGCTATCAAG } \\
\text { R: CGGTCACCACAATCAGGTACTT }\end{array}$ & 90 \\
\hline TERF1 & $\begin{array}{l}\text { F: ACAGCGCAGAGGCTATTATTC } \\
\text { R: TCAAACTGTGCATCAAGGGT }\end{array}$ & 121 \\
\hline TST & $\begin{array}{l}\text { F: TATCAGTGCTCAATGGTGGC } \\
\text { R: GTCCAGTGTGGCTTTGAAGA }\end{array}$ & 104 \\
\hline CD133 & $\begin{array}{l}\text { F: AAACCTGCAACAGCATCAGA } \\
\text { R: GGGATTGATAGCCCTGTTGG }\end{array}$ & 150 \\
\hline RALY & $\begin{array}{l}\text { F: CCCAAGTCCATCAACTCTCG } \\
\text { R: CTGCTCTCTTTAGCCCCTTG }\end{array}$ & 268 \\
\hline Prominin2 & $\begin{array}{l}\text { F: CTCCGTGAAGGTGAATGAGG } \\
\text { R: TTGTGCTCTGTCTTCACTCG }\end{array}$ & 159 \\
\hline
\end{tabular}

ALP, alkaline phosphatase; RUNX2, RUNX family transcription factor 2; COA3, cytochrome c oxidase assembly factor 3; APPL1, adaptor protein phosphotyrosine interacting with $\mathrm{PH}$ domain and leucine zipper 1; COL6A1, collagen type 6A1; TERF1, telomeric repeat binding factor 1; TST, thiosulfate sulfurtransferase; RALY, RALY heterogenous nuclear ribonucleoprotein; F, forward; R, reverse.

Cytiva) with $10 \% \mathrm{FBS}$. All cells were incubated at $37^{\circ} \mathrm{C}$ with $5 \% \mathrm{CO}_{2}$ in a humidified incubator. HOB, hES-MP 002.5 and M-7 cells were induced using osteoblast inducing conditional media (cat. no. CTCC Y001; Wuxi Puhe Biomedical Technology Co., Ltd.) for 14 days.

Cell transfection. COL6A1 pcRNA3.1(+) overexpression plasmid $(3,105 \mathrm{bp})$, empty vector pcDNA3.1(+), COL6A1 short hairpin (sh)RNA (sh-COL6A1) and sh-negative control (sh-NC) were purchased from Synbio Technologies. The sequences of the shRNAs targeting COL6A1 were 5'-GCC TGCAGAACTTCGAGATTG-3' and 5'-CAATCTCGAAGT TCTGCAGGC-3'; the sequence of sh-NC was 5'-CCTTCT GTTCGTGGTACACCG-3'. HARA cells $\left(5 \times 10^{4}\right.$ cells/well) in a 6-well plate were transfected with COL6A1-overexpression plasmid (500 ng/ $\mu \mathrm{l})$ or the empty vector (500 ng/ $\mu \mathrm{l})$; HARA-B4 cells $\left(5 \times 10^{4}\right.$ cells/well) in a 6 -well plate were transfected with sh-COL6A1 (40 ng/ $\mu$ l) or sh-NC (40 ng/ $\mu \mathrm{l})$. All transfections were performed using Lipofectamine ${ }^{\circledR} 2000$ (Invitrogen; Thermo Fisher Scientific, Inc.) at $37^{\circ} \mathrm{C}$ for $48 \mathrm{~h}$ according to the manufacturer's protocol. After transfection for $48 \mathrm{~h}$, the 

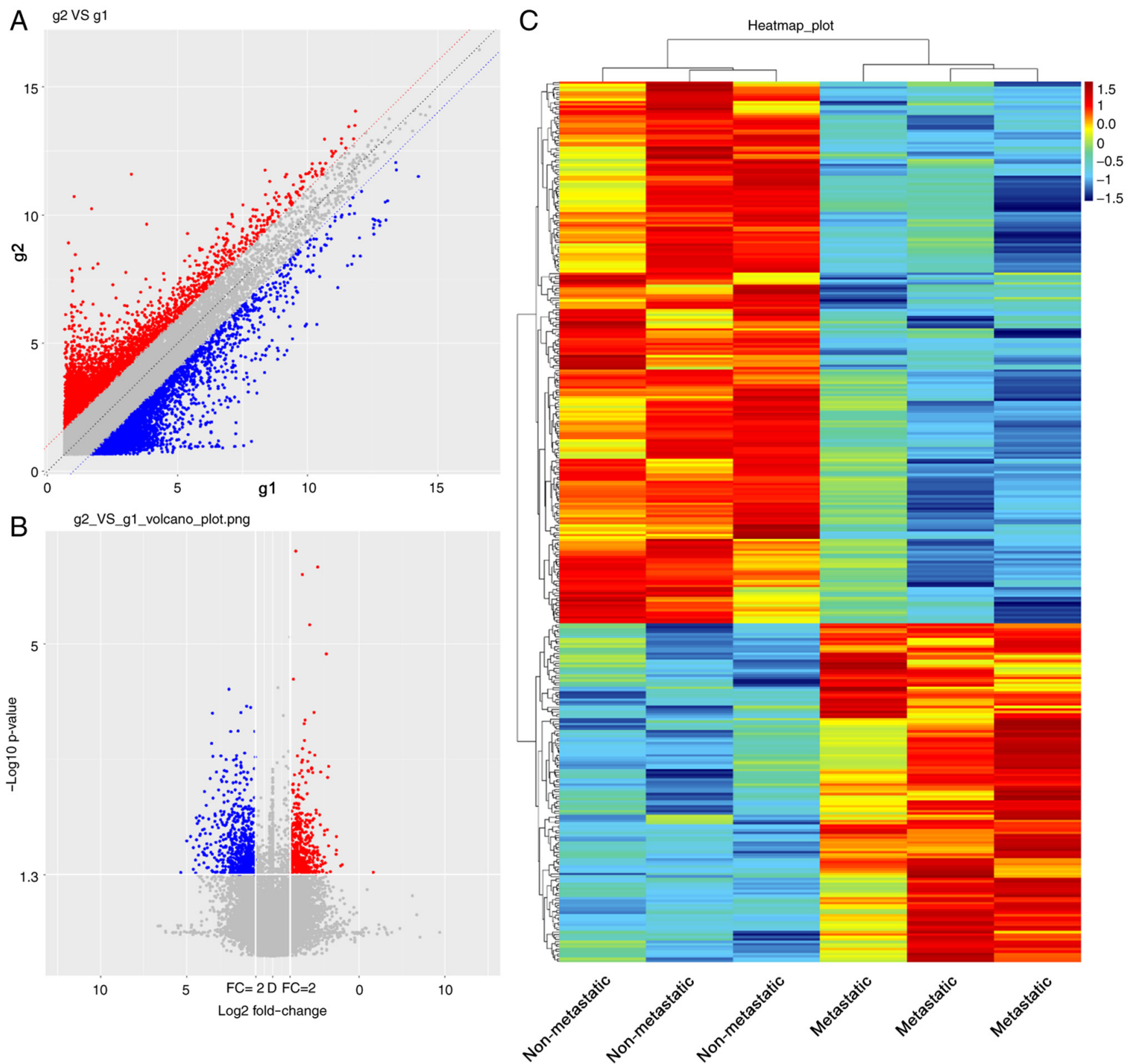

Figure 1. Expression profile of the DEGs between the NSCLC tissue samples with and without bone metastases. (A) Scatter plot representing the overall distribution of the two sets of data. Red, upregulated genes; blue, downregulated genes. (B) Volcano plot of the significant DEGs between NSCLC tissue samples with or without bone metastases. (C) Heatmap of the expression profile of the DEGs. DEG, differentially expressed gene; NSCLC, non-small cell lung cancer; FC, fold-change.

transfection efficiency was determined using RT-qPCR and the subsequent experiments were also conducted.

\section{Cell proliferation assay. The Cell Counting Kit-8 (CCK-8)} assay was used to assess cell proliferation. HARA and HARA-B4 cells $\left(2 \times 10^{3}\right.$ cells/well) were plated in 96-well plates and transfected as aforementioned for $24 \mathrm{~h}$. After additional cultures for $0,24,48$ or $72 \mathrm{~h}$ at $37^{\circ} \mathrm{C}$, each well was added with a total of $10 \mu \mathrm{l}$ CCK-8 solution (Dojindo Molecular Technologies, Inc.). After incubation for $3 \mathrm{~h}$ at $37^{\circ} \mathrm{C}$, the optical density was measured at $450 \mathrm{~nm}$. For the colony formation assays, the transfected HARA and HARA-B4 cells $\left(1 \times 10^{3}\right.$ cells/well) were plated in a 6 -well plate and routinely cultured for 14 days. Cell colonies were fixed with $4 \%$ paraformaldehyde (Beyotime, cat. no. P0099) at room temperature for $15 \mathrm{~min}$ and stained using $0.1 \%$ crystal violet at room temperature for $10 \mathrm{~min}$. The colonies (comprising $>50$ cells) were observed and calculated using a light microscope (DP72; Olympus Corporation) (magnification, x100).

Transwell assay. Transwell invasion assays were performed as previously described (25), using Transwell inserts (BD Biosciences) pre-coated with Matrigel at $37^{\circ} \mathrm{C}$ for $30 \mathrm{~min}$. Briefly, the transfected HARA and HARA-B4 cells ( $3 \times 10^{4}$ cells) in serum-free medium were added into the top of Transwell chambers, while medium with $15 \%$ FBS was added to the lower chamber. After a $24 \mathrm{~h}$ incubation, we removed the non-invading cells, and the invaded cells were fixed with $95 \%$ ethanol for $15 \mathrm{~min}$ and stained with $0.1 \%$ crystal violet for $5 \mathrm{~min}$. The invaded cells in 5 fields were obtained under a light microscope (DP72; Olympus Corporation) (magnification, x100). 
A

100.

GO classification

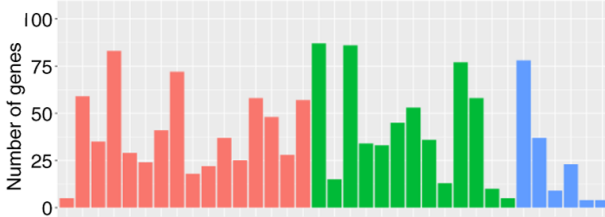

GO_domain

Biological_process

Molecular_function

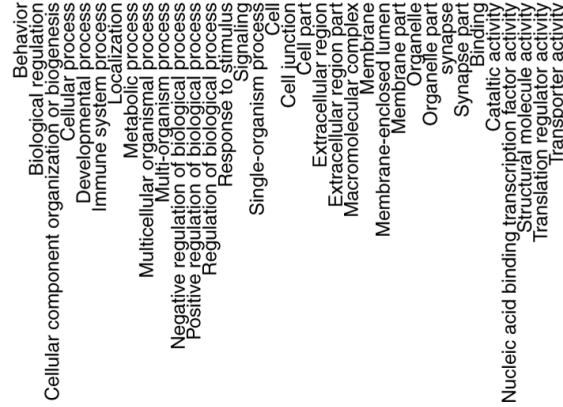

B

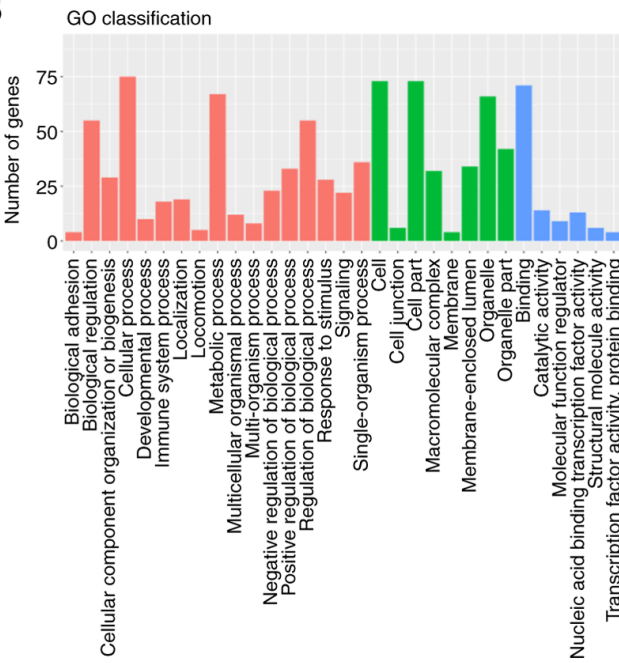

GO_domain

Biological_process

Molecular function

C

Top 30 of pathway enrichment

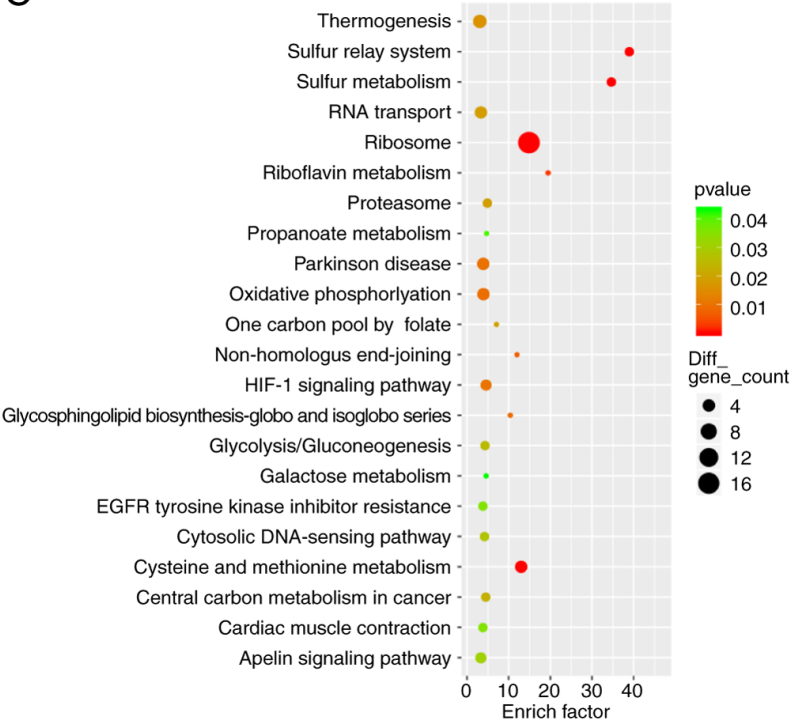

D Top 30 of pathway enrichment

Vimentin B6 metabolism Transcriptional misregulation in cancerSulfur relay system

RNA polymerase

Ribosome biogenesis in eukaryotes -

Ribosome-

Regulation of lipolysis in adipocytes

Propanoate metabolism

Mitophagy-animal

Glycosphingolipid biosynthesis-ganglio serie

Fluid shear stress and atherosclerosis

Cocaine addiction

Bile secretion

Autophagy-other

Autophagy-animal

Apoptosis

Acute myeloid leukemia

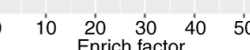

Diff-
gene
count

$\cdot 1.0$

$\dot{0} 0.0$

0.5

2.0

3.0

pvalue

0.04

0.04
0.03

0.02

Figure 2. GO and KEGG analysis of DEGs. (A and B) GO analysis of the (A) upregulated and (B) downregulated genes in NSCLC tissues with bone metastases. (C and D) KEGG pathway enrichment analysis of the (C) upregulated and (D) downregulated genes in NSCLC tissues with bone metastases. GO, Gene Ontology; KEGG, Kyoto Encyclopedia of Genes and Genomes; DEG, differentially expressed gene; NSCLC, non-small cell lung cancer.

Alizarin red and ALP staining. A total of $1 \times 10^{3} \mathrm{HOB}, \mathrm{hES}-\mathrm{MP}$ 002.5 or M-7 cells were plated per a well in a 96 -well plate. Following osteogenic induction for 14 days, the cells were stained using an Alizarin Red Staining kit (cat. no. CTCC JD001; Wuxi Puhe Biomedical Technology Co.,Ltd.), and ALP staining was performed using a specific kit (cat. no. CTCC 
A
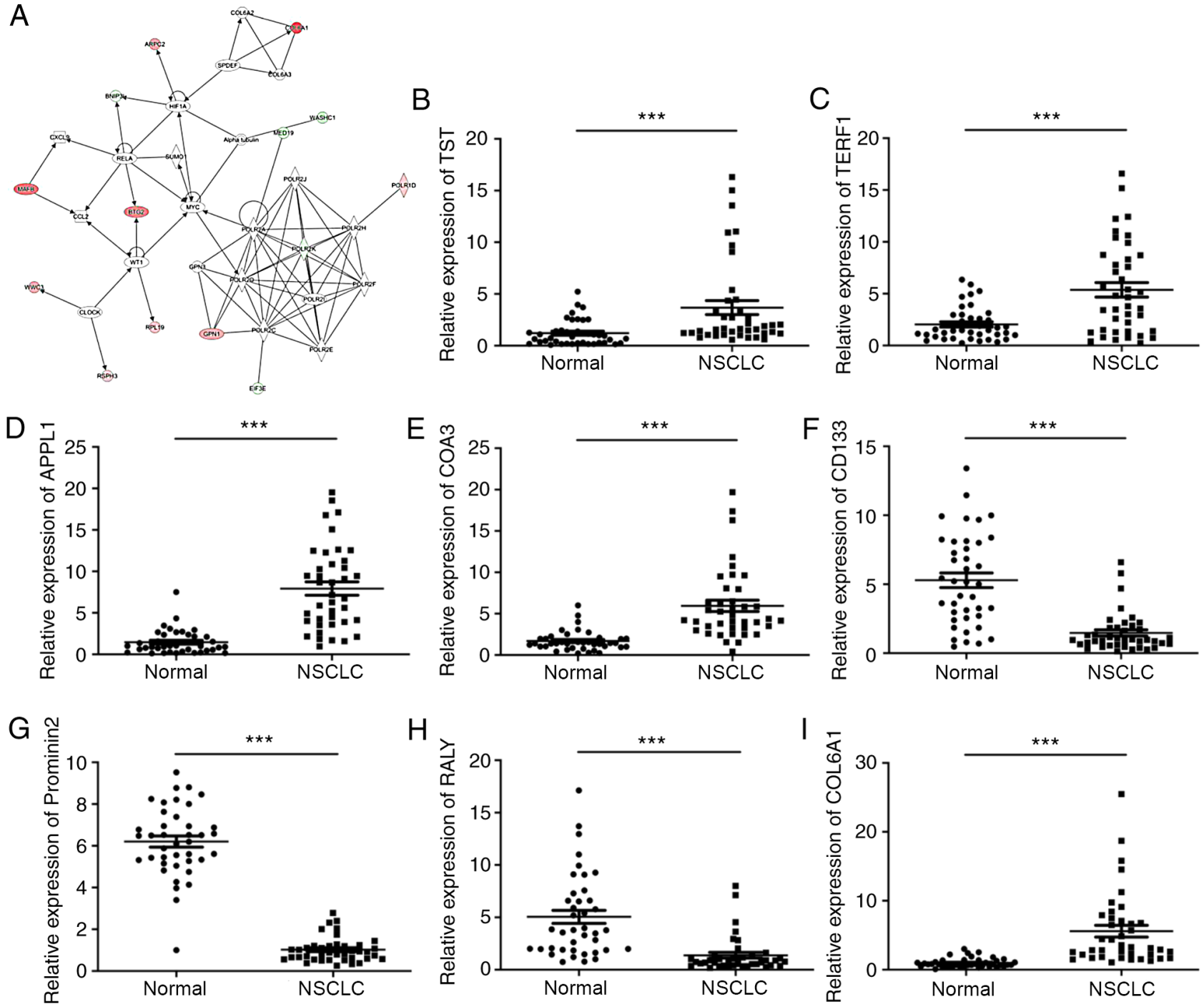

Figure 3. Network analysis using IPA and verification of the eight most differentially expressed genes using RT-qPCR in NSCLC. (A) Top networks of genes were displayed using IPA of NSCLC tissue samples with bone metastases. (B-I) RT-qPCR analysis was performed to confirm the expression levels of (B) TST, (C) TERF1, (D) APPL1, (E) COA3, (F) CD133, (G) Prominin 2, (H) RALY and (I) COL6A1 in NSCLC tissues and normal tissues. ${ }^{* * *} \mathrm{P}<0.001$. IPA, Ingenuity Pathway Analysis; RT-qPCR, reverse transcription-quantitative PCR; COL6A1, collagen type 6A1; TST, thiosulfate sufurtransferase; APPL1, adaptor protein phosphotyrosine interacting with PH domain and leucine zipper 1; COA3, cytochrome c oxidase assembly factor 3; TERF1, telomeric repeat-binding factor 1; RALY, RALY heterogenous nuclear ribonucleoprotein.

JD002; Wuxi Puhe Biomedical Technology Co., Ltd.). Both kits were used according to the manufacturer's instructions.

Cell adhesion assay. As described in a previous study (26), HOB, hES-MP 002.5 and M-7 cells were cultured in 6-well plates. A total of $1 \times 10^{3}$ HARA-B4 cells expressing COL6A1 overexpression plasmid were co-cultured with HOB, hES-MP 002.5 or M-7 cells for $30 \mathrm{~min}$ at $37^{\circ} \mathrm{C}$ with $5 \% \mathrm{CO}_{2}$. The treated HARA-B4 cells ( $1 \times 10^{3}$ cells/well) were overlaid directly in a dish and incubated for $30 \mathrm{~min}$ at $37^{\circ} \mathrm{C}$ with $5 \% \mathrm{CO}_{2}$. The cells were subsequently washed with PBS and fixed with $4 \%$ paraformaldehyde at room temperature for $15 \mathrm{~min}$. The adherent GFP-expressing cells in 5 fields were observed and counted under a fluorescence microscope (magnification, x100).

Statistical analysis. All measurement data are represented as mean \pm SD of 3 experimental repeats. Statistical analysis was performed using GraphPad Prism version 8 (GraphPad
Software, Inc.). Differences between groups were compared using paired or unpaired Student's t-test or one-way ANOVA followed by Bonferroni's correction. Data were derived from at least three independent experiments. $\mathrm{P}<0.05$ was considered to indicate a statistically significant difference.

\section{Results}

DEGs between NSCLC tissue samples with or without bone metastases. In order to analyze the expression profile of genes in NSCLC with bone metastasis, microarray analysis was performed on NSCLC tissue samples with and without bone metastases. First, principal components analysis (21) demonstrated a segregation between the non-metastatic and metastatic NSCLC tissue samples (Fig. S1). Scatter plot analysis of the overall distribution of data for the upregulated (red), downregulated (blue) and unchanged (gray) genes in Fig. 1A further highlighted the differences between the samples. 

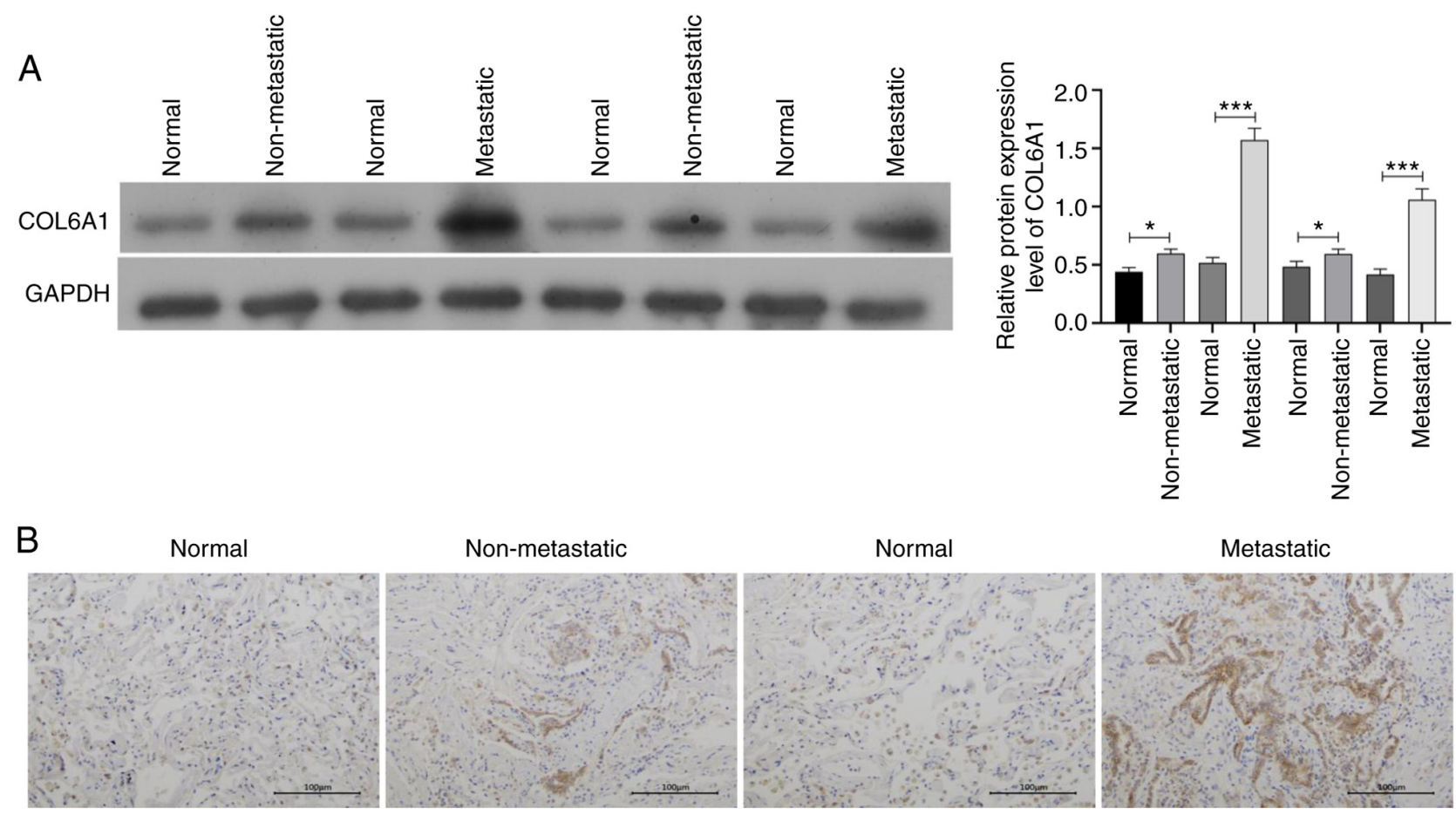

Figure 4. COL6A1 is highly expressed in NSCLC tissue samples with bone metastases. (A) COL6A1 expression was determined by western blotting in normal, NSCLC tissues without bone metastasis and NSCLC tissues with bone metastasis. (B) Immunohistochemistry analysis of COL6A1 expression in paired normal lung tissues and NSCLC tissues with and without bone metastases. Magnification, $\mathrm{x} 100$; scale bar, $100 \mu \mathrm{m} .{ }^{*} \mathrm{P}<0.05,{ }^{* * * *} \mathrm{P}<0.001$. NSCLC, non-small cell lung cancer; COL6A1, collagen type 6A1.

A volcano plot was generated to display the significant DEGs between NSCLC tissue samples with or without bone metastases (Fig. 1B). A total of 364 DEGs were identified, including 140 upregulated and 224 downregulated genes in NSCLC tissue samples with bone metastases using the cut-off criteria $\mid \log _{2} \mathrm{FCl}>2.0$ and $\mathrm{P}<0.05$. The expression profile of the DEGs is presented as a heatmap (Fig. 1C). Additional detailed information on the 140 upregulated genes is presented in Table SI, and the detailed information on the 224 downregulated genes is presented in Table SII.

GO and KEGG analyses of DEGs between NSCLC tissue samples with or without bone metastases. GO and KEGG analyses of the DEGs were performed. Comparing the NSCLC tissue samples with and without bone metastases, the GO analysis of the upregulated genes exhibited significant enrichment of 16 biological processes (BPs), 13 cellular components (CCs) and six molecular functions (MFs). The top three BPs included 'cellular process', 'metabolic process' and 'biological regulation'; the top three CCs included 'cell', 'cell part' and 'organelle'; and the top three MFs included 'binding', 'catalytic activity' and 'structural molecule activity' (Fig. 2A). GO analysis of the downregulated genes revealed significant enrichment of 17 BPs, eight CCs and six MFs. The top three BPs included 'cellular process', 'metabolic process' and 'biological regulation'; the top $3 \mathrm{CCs}$ included 'cell', 'cell part' and 'organelle'; and the top three MFs included 'binding', 'catalytic activity' and 'nucleic acid binding transcription factor activity' (Fig. 2B). The upregulated genes were primarily concentrated in five KEGG pathways: 'Ribosome', 'Cysteine and methionine metabolism', 'oxidative phosphorylation', 'Parkinson's disease', and 'thermogenesis' (Fig. 2C). The downregulated genes were primarily concentrated in 'transcriptional misregulation in cancer', 'ribosome', 'mitophagy-animal', 'bile secretion' and 'apoptosis' pathways (Fig. 2D).

Network analysis using IPA. IPA analysis was used to analyze the DEGs of the two NSCLC group samples. The top five pathways that were functionally associated with diseases and biofunctions included 'Synthesis of protein', 'Translation', 'Expression of protein', 'Translation of protein' and 'Nonsense-mediated mRNA decay' (Table SIII). The top-ranked ingenuity canonical pathway was 'EIF2 Signaling', which contains several key molecules, including eukaryotic initiation factor 3 subunit (EIF3)E, EIF3I, phosphoinositide-3-kinase regulatory subunit 5 , ribosomal protein $\mathrm{L}$ (RPL)10A and RPL12 (Table SIV). Furthermore, upstream transcript regulators including HR lysine demethylase and nuclear receptor corepressor, SAM pointed domain-containing ETS transcription factor (SPDEF), JunD proto-oncogene AP-1 transcription factor subunit, SMAD7, twist family bHLH transcription factor 1 , sterol regulatory element binding transcription factor 1, SMAD3, Fos proto-oncogene AP-1 transcription factor subunit and huntingtin were also identified (Table SV). As presented in Fig. 3A, the networks of DEGs of the two groups of samples contained several key genes implicated in cell proliferation ( $\alpha$-tubulin, hypoxia-inducible factor 1 subunit $\alpha$ and Myc), signaling [clock circadian regulator, RNA polymerase I and III subunit D (POLR1D), RNA polymerase II subunit (POLR2)A, POLR2C, POLR2D, POLR2E, POLR2F, POLR2H, POLR2J and POLR2K] and metabolism (COL6A2, collagen type VI $\alpha 3$ chain, GPN-loop GTPase 3, MAF bZIP 
Table II. Associations between COL6A1 expression levels and clinicopathological characteristics in NSCLC patients ( $\mathrm{n}=40$ ).

\begin{tabular}{|c|c|c|c|c|}
\hline \multirow[b]{2}{*}{ Characteristic } & \multicolumn{2}{|c|}{ COL6A1 expression } & \multirow[b]{2}{*}{$\chi^{2}$} & \multirow[b]{2}{*}{ P-value } \\
\hline & $\operatorname{High}(\mathrm{n}=20)$ & Low $(n=20)$ & & \\
\hline Sex & & & 0.4167 & 0.5186 \\
\hline Male & 13 & 11 & & \\
\hline Female & 7 & 9 & & \\
\hline Age, years & & & 1.026 & 0.3112 \\
\hline$\geq 60$ & 15 & 12 & & \\
\hline$<60$ & 5 & 8 & & \\
\hline Smoking & & & 0.4396 & 0.5073 \\
\hline Yes & 12 & 14 & & \\
\hline No & 8 & 6 & & \\
\hline Tumor size, $\mathrm{cm}$ & & & 1.29 & 0.256 \\
\hline$\geq 3$ & 6 & 3 & & \\
\hline$<3$ & 14 & 17 & & \\
\hline $\begin{array}{l}\text { Tumor-Node-Metastasis } \\
\text { stage (8th edition) }(45,46)\end{array}$ & & & 5.227 & 0.0222 \\
\hline I-II & 4 & 11 & & \\
\hline III-IV & 16 & 9 & & \\
\hline Bone metastasis & & & 4.912 & 0.0267 \\
\hline Yes & 13 & 6 & & \\
\hline No & 7 & 14 & & \\
\hline Other metastasis & & & 5.013 & 0.0252 \\
\hline Yes & 12 & 5 & & \\
\hline No & 8 & 15 & & \\
\hline Tumor type & & & 0.9207 & 0.3373 \\
\hline Squamous & 7 & 10 & & \\
\hline Adenocarcinoma & 13 & 10 & & \\
\hline
\end{tabular}

COL6A1, collagen type 6A1.

transcription factor $\mathrm{B}$, RELA proto-oncogene $\mathrm{NF}-\kappa \mathrm{B}$ subunit, SPDEF, small ubiquitin like modifier 1, WASH complex subunit 1 and WT1 transcription factor).

Identification of eight genes with the greatest differences in expression. To validate the accuracy of the microarray data, the expression levels of COL6A1, thiosulfate sulfurtransferase (TST), adaptor protein phosphotyrosine interacting with $\mathrm{PH}$ domain and leucine zipper 1 (APPL1), cytochrome $c$ oxidase assembly factor 3 (COA3), telomeric repeat binding factor 1 (TERF1), Prominin 2, RALY heterogenous nuclear ribonucleoprotein (RALY) and CD133 were evaluated in NSCLC tissues and normal tissues using RT-qPCR analysis. The expression levels of COL6A1, TST, APPL1, COA3 and TERF1 were significantly increased, whereas the levels of Prominin 2, RALY and CD133 were significantly reduced in NSCLC tissues compared with those in the normal tissues (Fig. 3B-I).

COL6A1 expression is upregulated in NSCLC tissue samples with bone metastases. COL6A1 was the most highly expressed gene in samples with bone metastases compared with those without bone metastases. As presented in Fig. 4A, compared with those in normal lung tissues, the expression levels of COL6A1 were significantly increased in NSCLC tissues without or with bone metastasis, and COL6A1 level appeared to be upregulated in metastatic NSCLC tissues compared with those in the non-metastatic NSCLC tissues. High expression levels of COL6A1 were associated with the Tumor-Node-Metastasis stage and with metastasis to the bone and other organs (Table II). Consistent with these results, the IHC analysis revealed that high protein expression levels of COL6A1 were also observed in the metastatic NSCLC tissues (Fig. 4B), suggesting that COL6A1 may serve an important role in the process of bone metastasis.

Effects of COL6A1 overexpression and knockdown on the proliferation and invasion of HARA and HARA-B4 cells. To further analyze the roles of COL6A1 on NSCLC cells, COL6A1 expression in normal lung epithelial cells (HPAEpic) and five NSCLC cancer cell lines was examined. As demonstrated in Fig. 5A, the expression of COL6A1 was higher in the five NSCLC cell lines (A549, HARA, NCI-H226, HARA-B4 


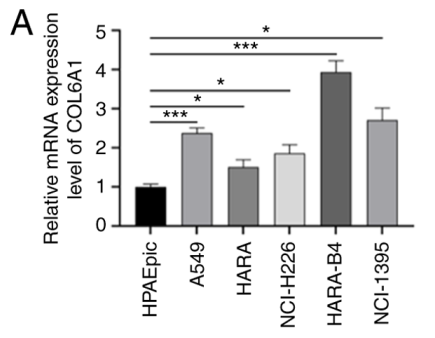

B

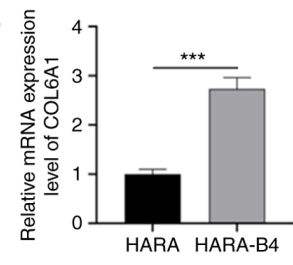

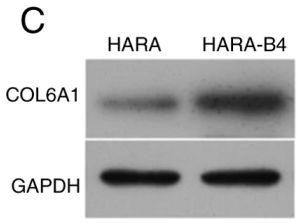

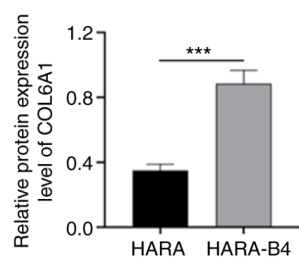

D

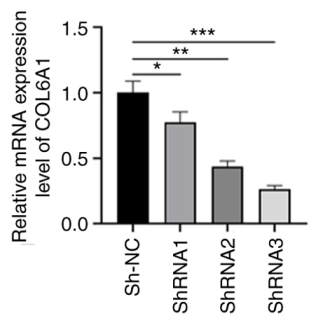

E

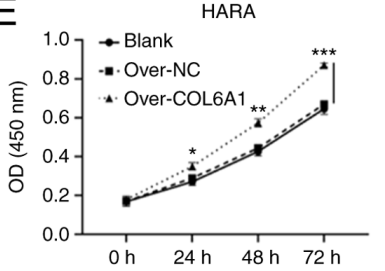

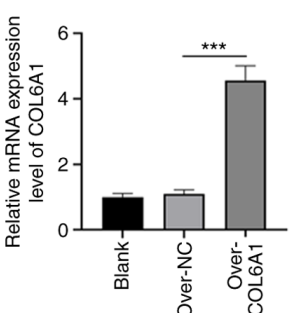

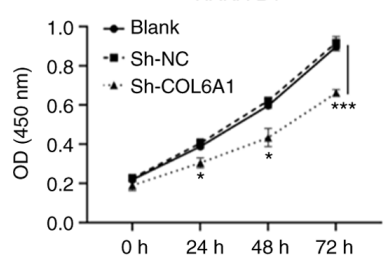

F
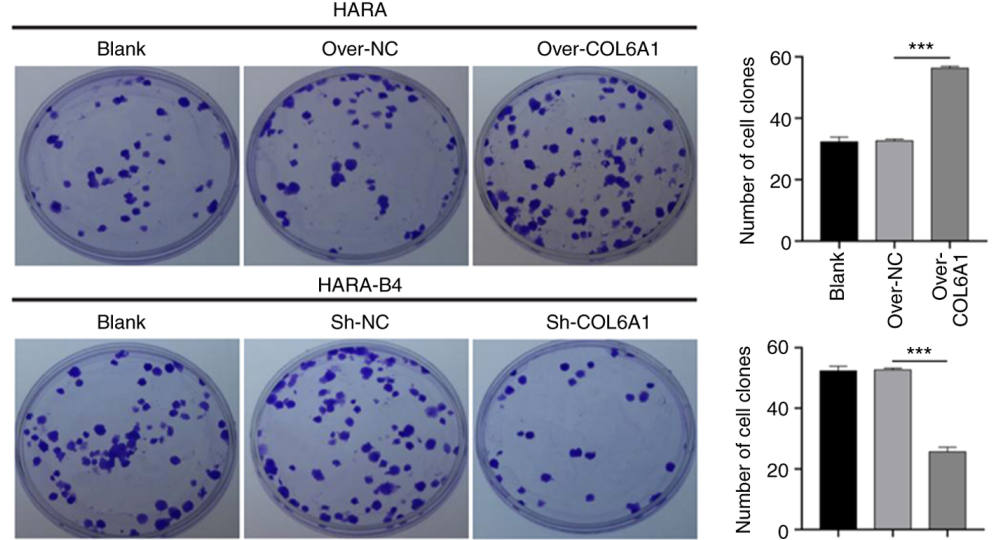

Sh-NC

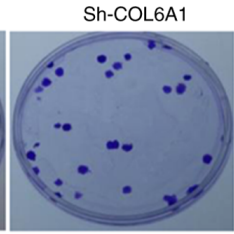

G
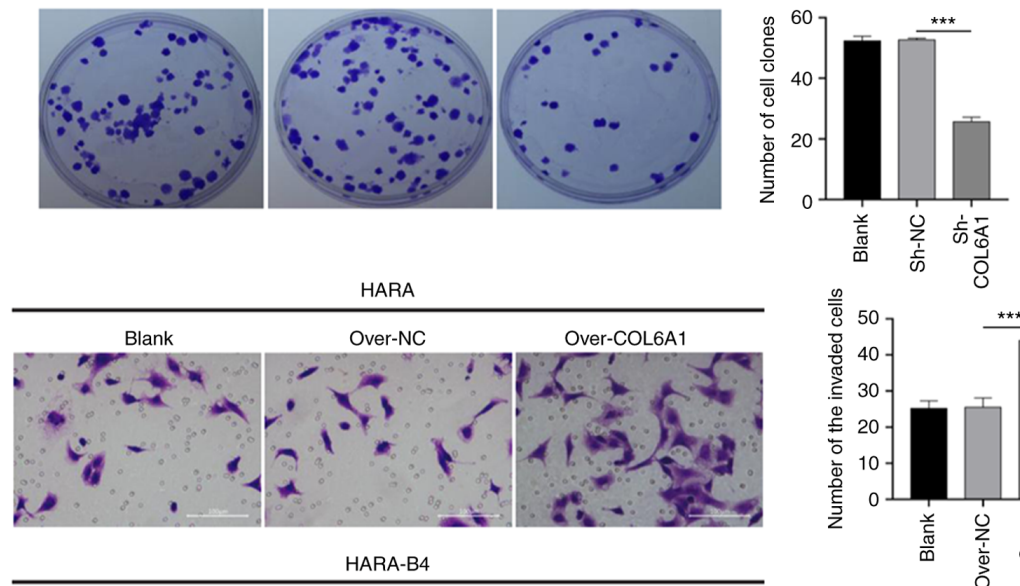

Sh-NC

Sh-COL6A1
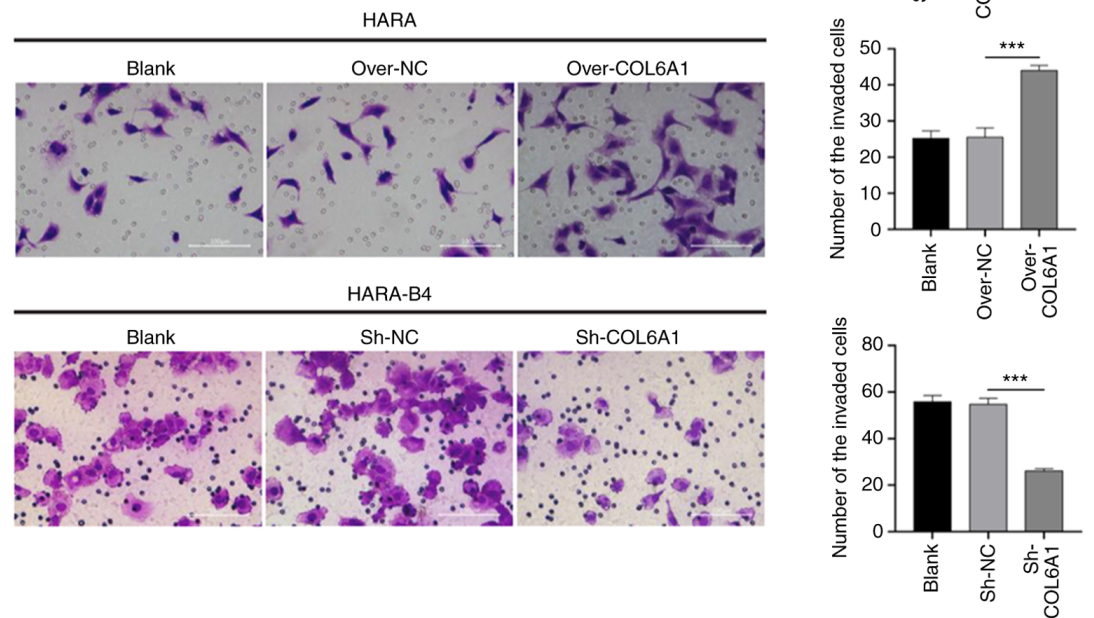

Figure 5. Effects of COL6A1 overexpression or knockdown on the proliferation and invasion of HARA or HARA-B4 cells. (A) RT-qPCR analysis of COL6A1 expression levels in HPAEpic normal lung cells and A549, HARA, NCI-H226, HARA-B4 and NCI-1395 lung cancer cell lines. (B and C) Verification of COL6A1 expression was performed using (B) RT-qPCR and (C) western blot analysis in HARA and HARA-B4 cells. (D) COL6A1 was silenced in HARAD B4 cells and overexpressed in HARA cells, and the expression change of COL6A1 was confirmed using RTDqPCR analysis. (E) The proliferation of the COL6A1-overexpressing HARA cells and COL6A1-knockdown HARA-B4 cells was assessed using a Cell Counting Kit-8 assay. (F) Following COL6A1 overexpression in HARA cells and COL6A1 knockdown in HARA-B4 cells, the cell proliferative capacity was verified using a colony formation assay. (G) Transwell assays were performed to identify the effects of COL6A1 overexpression or knockdown on the invasive ability of HARA or HARA-B4 cells. ${ }^{*} \mathrm{P}<0.05,{ }^{* * *} \mathrm{P}<0.01$ and ${ }^{* * *} \mathrm{P}<0.001$. RT-qPCR, reverse transcription-quantitative PCR; COL6A1, collagen type 6A1. 
A

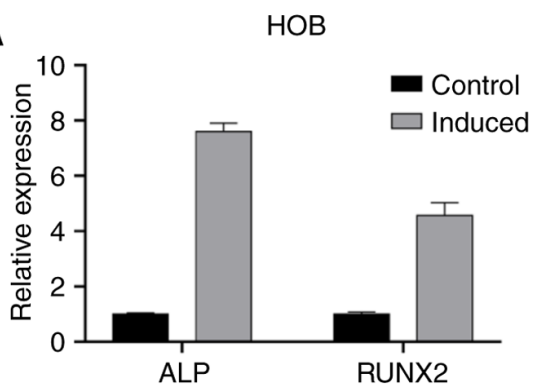

B

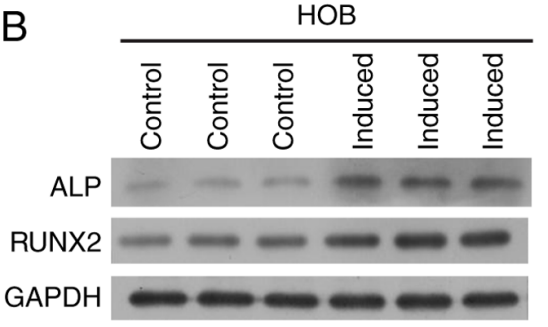

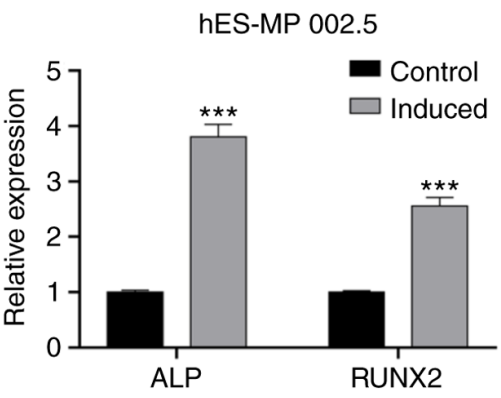
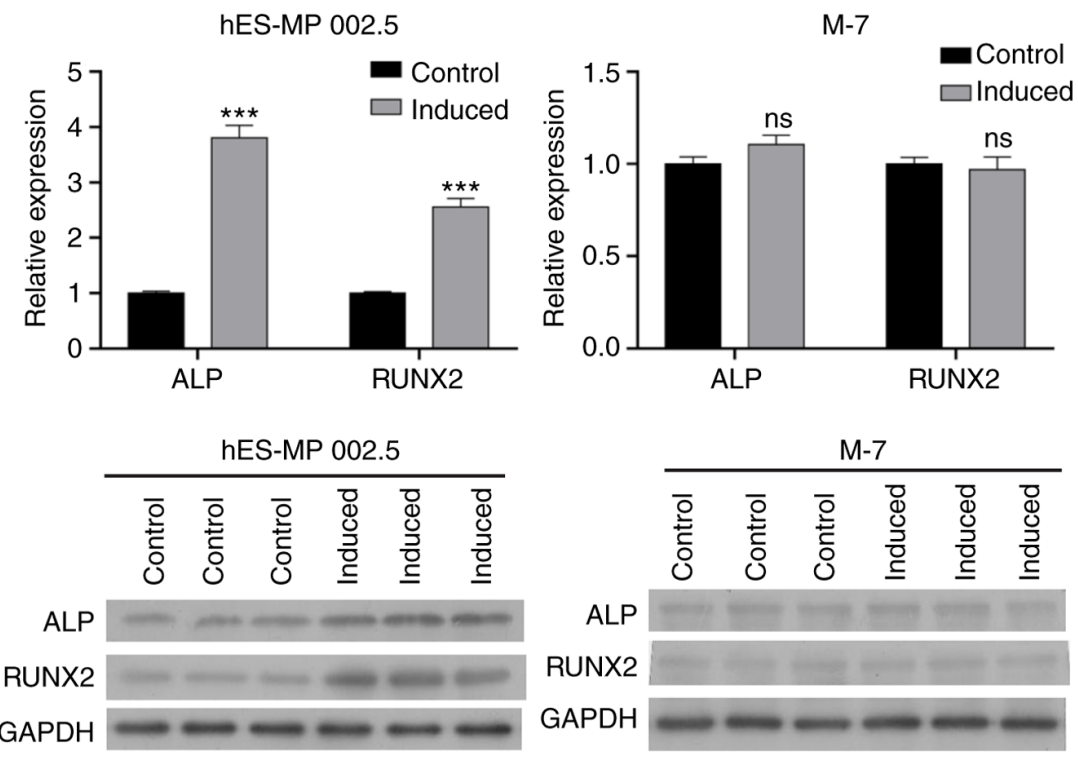

C

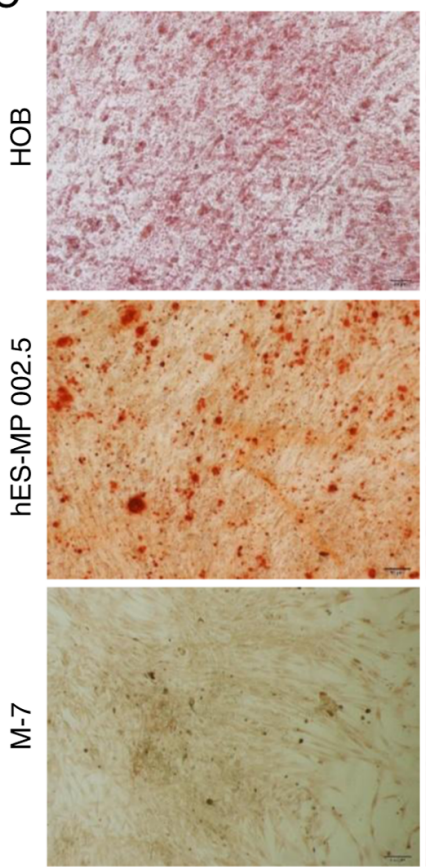

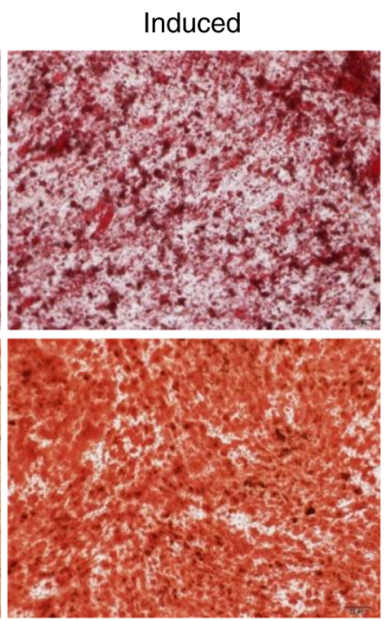

D
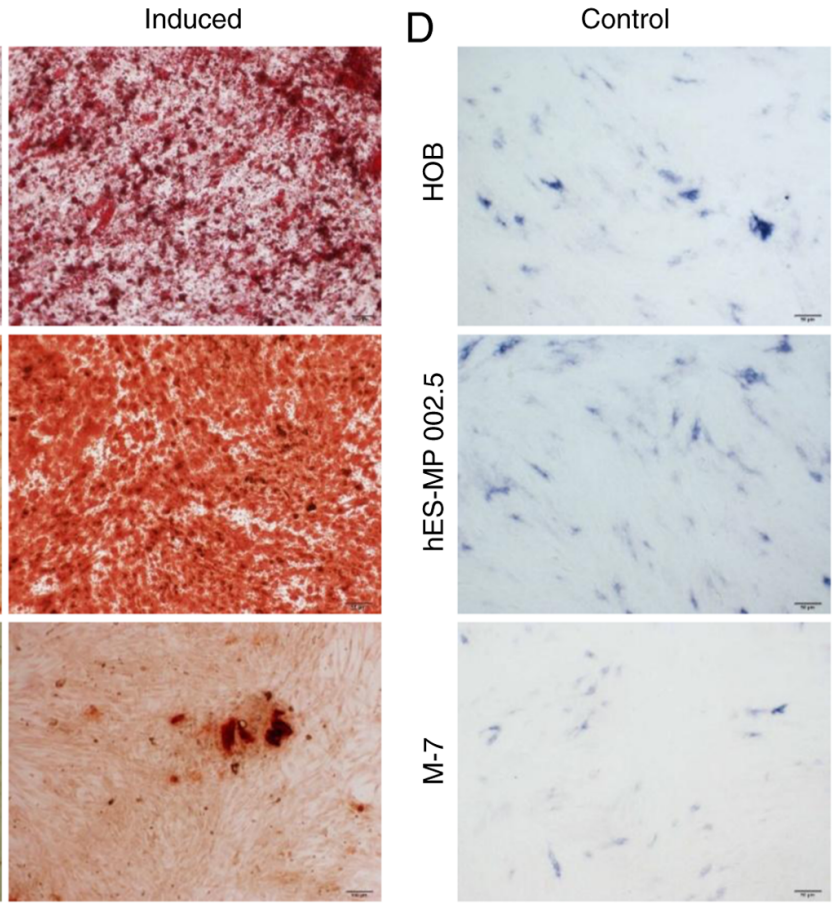

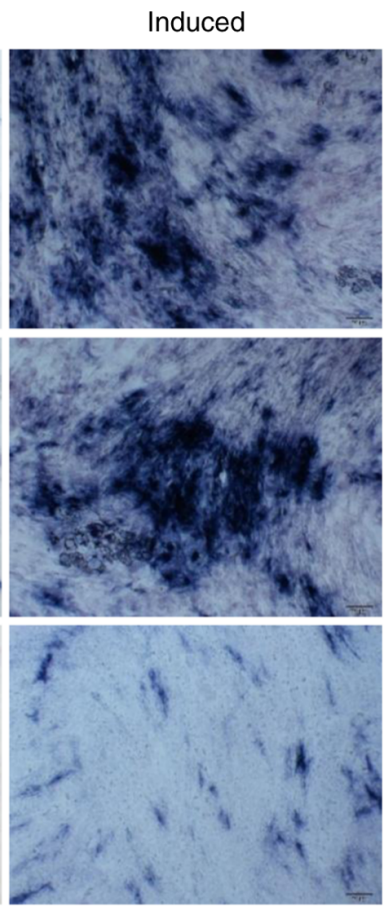

Figure 6. Induction and identification of osteoblasts. HOB, hES-MP 002.5 and M-7 cells were induced using the osteoblast-inducing conditional media for 14 days. (A) Reverse transcription-quantitative PCR and (B) western blot analysis were used to analyze the expression levels of ALP and RUNX2 in induced and uninduced cells. (C) Calcium deposition was examined using Alizarin Red Staining in HOB, hES-MP 002.5 and M-7 cells following osteogenic induction. (D) ALP activity was determined using ALP staining in the induced and uninduced HOB, hES-MP 002.5 and M-7 cells. Magnification, x100; scale bar, $100 \mu \mathrm{m} .{ }^{* * * *} \mathrm{P}<0.001$ vs. control; ns, not significant. ALP, alkaline phosphatase; RUNX2, RUNX family transcription factor 2.

and NCI-1395) compared with those in the HPAEpic cells. Amongst the five NSCLC cell lines, HARA-B4 cells exhibited the highest levels of COL6A1 expression, whereas HARA cells exhibited the lowest levels.

Compared with those in the HARA cells, the mRNA and protein expression levels of COL6A1 were notably higher in the HARA-B4 cells (Fig. 5B and C). COL6A1 expression was thus overexpressed in HARA and knocked down in HARA-B4 cells using an overexpression plasmid and shRNA, respectively. The results of the CCK- 8 assays demonstrated that overexpression of COL6A1 significantly enhanced the proliferation of HARA cells, whereas knockdown of COL6A1 notably reduced the proliferation of HARA-B4 cells compared with that in the corresponding control groups (Fig. 5D). Similarly, the colony formation assays revealed that overexpression of COL6A1 significantly increased the number of colonies formed by HARA cells compared with that in the control group, whereas the reverse effect was observed in the COL6A1 knockdown HARA-B4 cells (Fig. 5E). In addition, COL6A1 overexpression contributed to a significant increase in HARA cell invasion, and COL6A1 knockdown significantly reduced HARA-B4 cell invasion compared with that in the control groups (Fig. 5F). Therefore, COL6A1 may induce the proliferation and invasion of NSCLC cells. 
A HOB
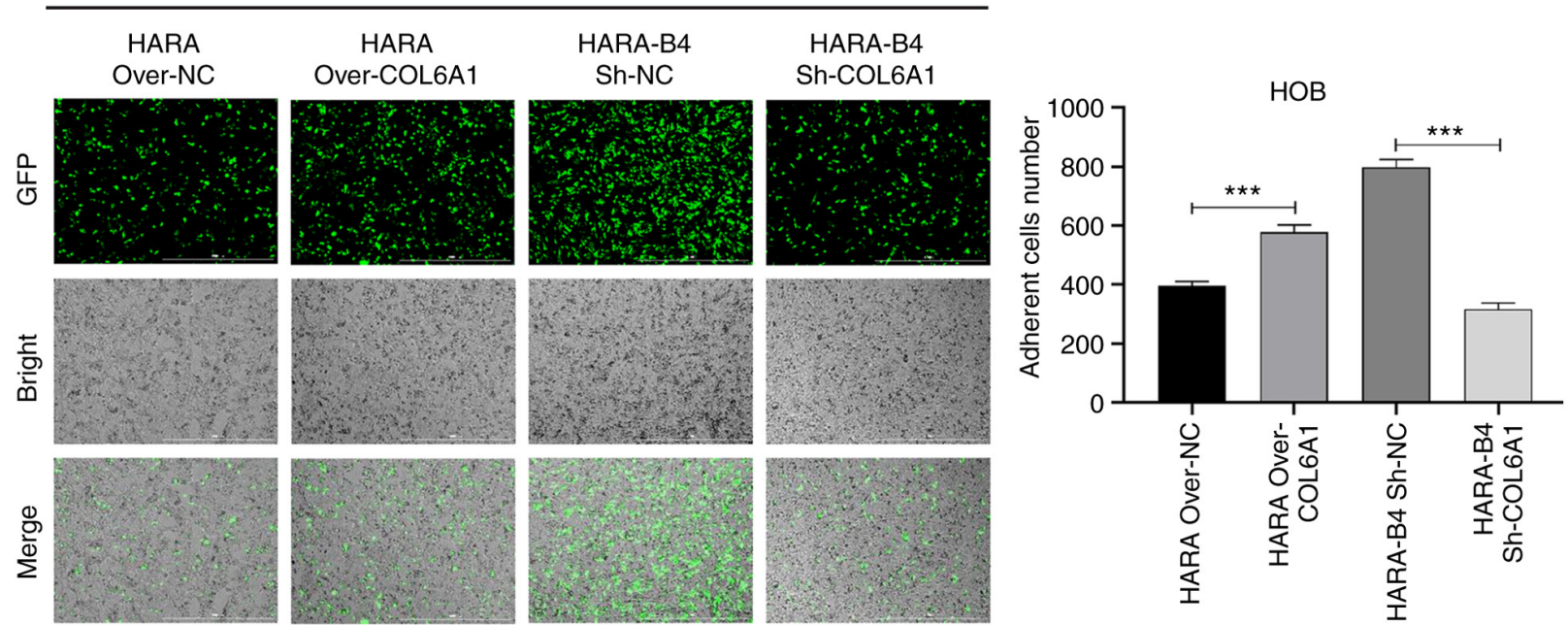

B
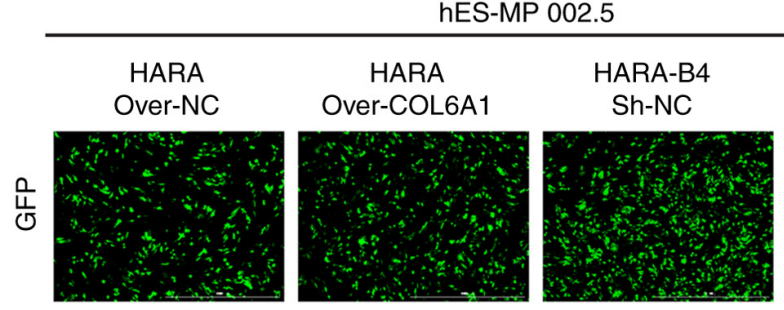

HARA-B4
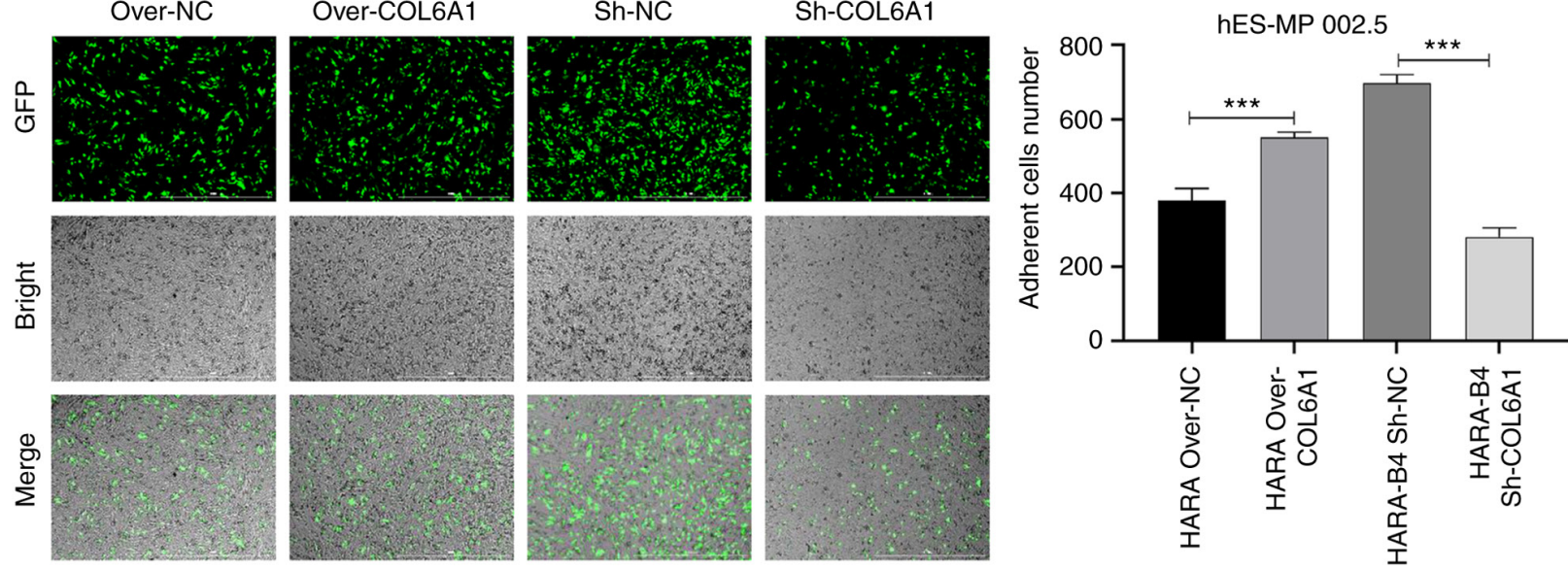

C
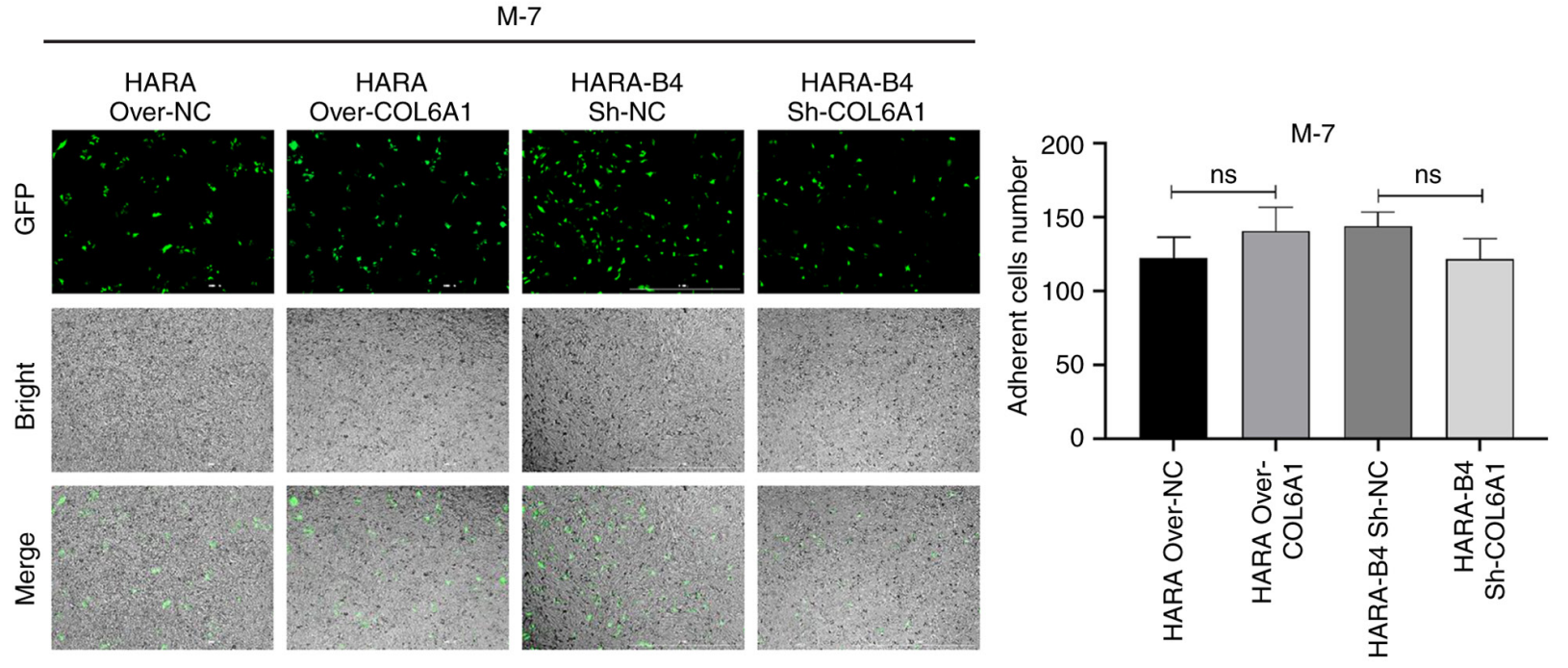

Figure 7. COL6A1 increases the adhesive ability of HARA and HARA-B4 cells after co-culture with HOB or hES-MP 002.5 cells. (A-C) The adhesive capacities of HARA cells transfected with the COL6A1 overexpression plasmid or empty vector and HARA-B4 cells transfected with sh-COL6A1 or sh-NC were assessed by counting the number of GFP-positive cells following co-culture with (A) HOB, (B) hES-MP 002.5 or (C) M-7 cells for 30 min. Magnification, $\mathrm{x} 100$; scale bar, $100 \mu \mathrm{m} .{ }^{* * *} \mathrm{P}<0.001$, COL6A1, collagen type 6A1; over, overexpression vector; sh, short hairpin RNA; NC, negative control; GFP, green fluorescent protein; ns, no statistical significance.

Identification of the osteogenic ability of various cell lines. In order to establish a model for the in vitro analysis of bone metastasis, the osteogenic abilities of HOB,hES-MP 002.5 and M-7 cells were investigated. Osteoblast-inducing conditional 
media was added to induce HOB, hES-MP 002.5 and M-7 cells for 14 days. RT-qPCR analysis results demonstrated that the expression levels of ALP and RUNX2 were notably increased in HOB- and hES-MP 002.5-induced cells compared with those in the respective control cells, whereas ALP and RUNX2 expression levels were not altered in the M-7 cells following induction (Fig. 6A). In addition, western blotting analysis also revealed that the levels of ALP and RUNX2 were higher in the osteogenic-induced HOB and hES-MP 002.5 cells compared with those in the control cells; in the M-7 cells, ALP and RUNX2 expression levels were low and were not altered (Fig. 6B). The degree of osteogenic differentiation was estimated in HOB, hES-MP 002.5 and M-7 cells. Firstly, Alizarin Red staining was used to assess calcium deposition in these cells. As demonstrated in Fig. 6C, HOB and hES-MP 002.5 cells exhibited weak osteoblastic activity under normal culture conditions, and a large number of osteoblasts were observed following osteogenic induction. No osteoblasts were present in the M-7 cells under normal culture conditions, and few osteoblasts were observed following induction. ALP staining was used to determine the ALP activity of HOB, hES-MP 002.5 and M-7 cells. ALP activity was enhanced in HOB and hES-MP 002.5 cells following osteogenic induction compared with that in the normally cultured cells. Following osteogenic induction, the ALP activity was slightly increased in the M-7 cells compared with that in uninduced cells (Fig. 6D).

COL6A1 promotes bone metastasis in vitro. To investigate the effect of COL6A1 on osteogenic differentiation and identify the effects of COL6A1 on cell adhesion, HOB, hES-MP 002.5 and M-7 cells were co-cultured with COL6A1-overexpressing HARA cells and COL6A1-knockdown HARA-B4 cells, and the number of GFP-expressing cells were counted. Compared with that in the negative control-transfected cells, overexpression of COL6A1 enhanced the adhesive capacity of HARA cells following co-culture with HOB and hES-MP 002.5 cells, whereas knockdown of COL6A1 significantly attenuated the adhesive capacity of HARA-B4 cells after co-culture with HOB and hES-MP 002.5 cells. However, COL6A1 did not alter the adhesive capacity of HARA-B4 cells following co-culture with M-7 cells (Fig. 7).

\section{Discussion}

NSCLC is a common malignant tumor, and the rates of morbidity and mortality are increasing (27). Tumor stage, lymph node and bone metastasis have been reported to be the primary factors negatively affecting the prognosis of patients with NSCLC $(28,29)$. To examine the gene markers and regulatory pathways associated with bone metastasis in patients with NSCLC, whole transcriptome expression microarray analysis was performed in the present study, and the gene expression profiles between NSCLC tissue samples with and without bone metastases were compared. Bioinformatics analysis was performed to identify the key genes and pathways associated with the development of bone metastasis. By comparing the differences in gene expression between the two groups of samples, 364 DEGs were identified, including 140 upregulated and 224 downregulated genes in NSCLC tissue samples relative to the non-metastatic tissue.
GO and KEGG analysis are commonly used methods to predict and identify target molecules and regulatory networks associated with disease occurrence (30-32). To determine the molecular regulatory network of DEGs and the biological functions of DEGs in NSCLC in the present study, GO and KEGG pathway enrichment analysis was performed. GO analysis revealed that the crucial biological processes of the DEGs in NSCLC tissue samples with bone metastases were primarily associated with 'cellular process', 'metabolic process' and 'biological regulation'. 'Binding' and 'catalytic activity' were also associated with bone metastasis in patients with NSCLC. In addition, KEGG enrichment analysis demonstrated that the DEGs in NSCLC tissue samples with bone metastases were primarily enriched in 'ribosome', 'apoptosis', 'cysteine and methionine metabolism' and 'transcriptional misregulation in cancer'. Additionally, the expression levels of COL6A1, TST, APPL1, COA3 and TERF1 were upregulated, whereas Prominin 2, RALY and CD133 were significantly downregulated in NSCLC tissue samples with bone metastases compared with those in non-metastatic samples. Amongst these DEGs, COL6A1 was the most significantly differentially expressed in NSCLC tissue samples with bone metastasis $(33,34)$.

COL6A1, which is located on chromosome 21 , is a crucial gene of the collagen family and encodes the $\alpha 1$ (VI) chain of type VI collagen. Type VI collagen is an extracellular matrix protein that serves crucial roles in maintaining the integrity of several types of tissues, prostate cancer tissues (35), cervical cancer tissues (36) and clear cell renal cell carcinoma tissues (37). COL6A1 has been demonstrated to regulate cellular functions such as migration, differentiation and survival by participating in various processes, including apoptosis, proliferation, angiogenesis, fibrosis and inflammation (38). Mutations of COL6A1 are associated with several musculoskeletal disorders, such as Bethlam myopathy and Ulrich congenital muscular dystrophy (39). Although COL6A1 is widely distributed in various tissues, its expression levels are markedly higher in pancreatic cancer tumor tissues with bone metastases compared with those in tissues without bone metastases (34). These findings suggest that COL6A1 may be involved in the progression of several types of cancer $(34,36,37,40,41)$. For example, a recent study has reported that the mRNA and protein expression levels of COL6A1 are high in lung tissues of patients with pulmonary fibrosis (42), suggesting an association between COL6A1 expression and NSCLC development. In addition, by utilizing quantitative secretome analysis, expression of COL6A1 has been demonstrated to be high in metastatic NSCLC cells, whereas COL6A1 knockdown inhibited the metastatic activity of cancer cells compared with the control group (43). Global secretome analysis of cell lines with varying bone metastatic ability from multiple types of cancer has identified COL6A1 as a secreted mediator of bone metastasis (44). The results of the present study further confirmed that the levels of COL6A1 were significantly upregulated in NSCLC tissues with bone metastases compared with those in tissues from patients without bone metastases. Additionally, it was demonstrated that COL6A1 accelerated the proliferation and invasion of NSCLC cells and significantly increased the adhesive ability of HARA-B4 cells to osteoblasts. Therefore, COL6A1 may be strongly associated with metastasis to the bone in patients with NSCLC. 
In conclusion, based on the comprehensive whole transcriptome expression microarray analysis, the present study revealed crucial genes and pathways that may be associated with the features of NSCLC with bone metastases. In particular, COL6A1 was demonstrated to increase the adhesive ability of HARA-B4 cells to osteoblasts. It is therefore hypothesized that COL6A1 may potentially serve as a novel therapeutic target for the treatment of patients with advanced NSCLC with bone metastases.

\section{Acknowledgements}

Not applicable.

\section{Funding}

No funding was received.

\section{Availability of data and materials}

The datasets generated for this study are available on the GEO database with the accession number GSE175601 (https://www. ncbi.nlm.nih.gov/geo/query/acc.cgi?ac c=GSE175601).

\section{Authors' contributions}

NL, ZMZ conceived and designed the study. NL, ZMZ, ML, XHC and YFL performed the experiments. NL, ZMZ and ML confirmed the authenticity of all the raw data. NL, WL and YFL analyzed and interpretated the data. NL wrote the manuscript. All authors read and approved the final manuscript.

\section{Ethics approval and consent to participate}

The study protocol used in the present study was approved by the Ethics Committee of the Third Hospital of Hebei Medical University. All patients signed the informed consent forms.

\section{Patient consent for publication}

Not applicable.

\section{Competing interests}

The authors declare that they have no competing interests.

\section{References}

1. Parkin DM, Bray F, Ferlay $\mathrm{J}$ and Pisani P: Global cancer statistics, 2002. CA Cancer J Clin 55: 74-108, 2005.

2. Ferlay J, Colombet M, Soerjomataram I, Mathers C, Parkin DM, Piñeros M, Znaor A and Bray F: Estimating the global cancer incidence and mortality in 2018: GLOBOCAN sources and methods. Int J Cancer 144: 1941-1953, 2019.

3. Ni Y, Ye X, Yang X, Huang G, Li W, Wang J, Han X, Wei Z, Meng $M$ and Zou Z: Microwave ablation for non-small cell lung cancer with synchronous solitary extracranial metastasis. J Cancer Res Clin Oncol 146: 1361-1367, 2020.

4. Nakahara Y, Hosomi Y, Shibuya M, Mitsufuji H, Katagiri M, Naoki K, Soejima K, Nogami N, Nagase S, Nishikawa M, et al: Multicenter study of zoledronic acid administration in non-small-cell lung cancer patients with bone metastasis: Thoracic oncology research group (TORG) 1017. Mol Clin Oncol 11: 349-353, 2019.
5. Oster G, Lamerato L, Glass AG, Richert-Boe KE, Lopez A, Chung K, Richhariya A, Dodge T, Wolff GG, Balakumaran A and Edelsberg J: Natural history of skeletal-related events in patients with breast, lung, or prostate cancer and metastases to bone: A 15-year study in two large US health systems. Support Care Cancer 21: 3279-3286, 2013.

6. Katakami N, Kunikane H, Takeda K, Takayama K, Sawa T, Saito H, Harada M, Yokota S, Ando K, Saito Y, et al: Prospective study on the incidence of bone metastasis (BM) and skeletal-related events (SREs) in patients (pts) with stage IIIB and IV lung cancer-CSP-HOR 13. J Thorac Oncol 9: 231-238, 2014.

7. Zhang L and Gong Z: Clinical characteristics and prognostic factors in bone metastases from lung cancer. Med Sci Monit 23: 4087-4094, 2017.

8. Lang J, Zhao Q, He Y and $\mathrm{Yu} \mathrm{X:} \mathrm{Bone} \mathrm{turnover} \mathrm{markers} \mathrm{and}$ novel biomarkers in lung cancer bone metastases. Biomarkers 23: 518-526, 2018.

9. Pontarollo G, Confavreux CB, Pialat JB, Isaac S, Forest F, Yvorel V, Maury JM, Girard N and Brevet M: Bone decalcification to assess programmed cell death ligand 1 expression in bone metastases of non-small cell lung cancers. J Bone Oncol 21: $100275,2020$.

10. Zhao H, Han KL, Wang ZY, Chen Y, Li HT, Zeng JL, Shen Z and Yao Y: Value of C-telopeptide-cross-linked Type I collagen, osteocalcin, bone-specific alkaline phosphatase and procollagen Type I N-terminal propeptide in the diagnosis and prognosis of bone metastasis in patients with malignant tumors. Med Sci Monit 17: CR626-CR633, 2011.

11. Yang S, Liu Y, Li MY, Ng CSH, Yang SL, Wang S, Zou C, Dong Y, Du J, Long X, et al: FOXP3 promotes tumor growth and metastasis by activating Wnt $/ \beta$-catenin signaling pathway and EMT in non-small cell lung cancer. Mol Cancer 16: 124, 2017.

12. Wei CH, Wu G, Cai Q, Gao XC, Tong F, Zhou R, Zhang RG, Dong JH, Hu Y and Dong XR: MicroRNA-330-3p promotes cell invasion and metastasis in non-small cell lung cancer through GRIA3 by activating MAPK/ERK signaling pathway. J Hematol Oncol 10: 125, 2017

13. Yuan J, Zhang G, Li X, Ma Q, Cheng W, Wang W, Zhang B, Hu T and Song G: Knocking down USP39 inhibits the growth and metastasis of non-small-cell lung cancer cells through activating the p53 pathway. Int J Mol Sci 21: 8949, 2020.

14. Ge L, Shao GR, Wang HJ, Song SL, Xin G, Wu M and Zhang FX: Integrated analysis of gene expression profile and genetic variations associated with ovarian cancer. Eur Rev Med Pharmacol Sci 19: 2703-2710, 2015.

15. Shi WY, Liu KD, Xu SG, Zhang JT, Yu LL, Xu KQ and Zhang TF: Gene expression analysis of lung cancer. Eur Rev Med Pharmacol Sci 18: 217-228, 2014

16. Liao $Y$, Yin $G$, Wang $X$, Zhong $P$, Fan $X$ and Huang $C$ : Identification of candidate genes associated with the pathogenesis of small cell lung cancer via integrated bioinformatics analysis. Oncol Lett 18: 3723-3733, 2019.

17. Ritchie ME, Belinda P, Wu D, Hu Y, Law CW, Shi W and Smyth GK: limma powers differential expression analyses for RNA-sequencing and microarray studies. Nucleic Acids Res 43: e47, 2015.

18. Püffeld M, Seiler C, Kuhlmann M, Sreenivasulu N and Butardo VM Jr: Analysis of developing rice grain transcriptome using the agilent microarray platform. Methods Mol Biol 1892: 277-300, 2019.

19. Eadie A, Vásquez I, Liang X, Wang X, Souders CL II, Chehouri JE, Hoskote R, Feswick A, Cowie AM, Loughery JR and Martyniuk CJ: Transcriptome network data in larval zebrafish (Danio rerio) following exposure to the phenylpyrazole fipronil. Data Brief 33: 106413, 2020.

20. Bolstad BM, Irizarry RA, Astrand M and Speed TP: A comparison of normalization methods for high density oligonucleotide array data based on variance and bias. Bioinformatics 19: 185-193, 2003.

21. Groth D, Hartmann S, Klie S and Selbig J: Principal components analysis. Methods Mol Biol 930: 527-547, 2013.

22. Dennis G Jr, Sherman BT, Hosack DA, Yang J, Gao W, Lane HC and Lempicki RA: DAVID: Database for annotation, visualization, and integrated discovery. Genome Biol 4: P3, 2003.

23. Livak KJ and Schmittgen TD: Analysis of relative gene expression data using real-time quantitative PCR and the 2(-Delta Delta C(T)) method. Methods 25: 402-408, 2001. 
24. Li O, Tormin A, Sundberg B, Hyllner J, Le Blanc K and Scheding S: Human embryonic stem cell-derived mesenchymal stroma cells (hES-MSCs) engraft in vivo and support hematopoiesis without suppressing immune function: Implications for off-the shelf ES-MSC therapies. PLoS One 8: e55319, 2013.

25. Liao S, Yang Y, Chen S, Bi Y, Huang Q, Wei Z, Qin A and Liu B IL-24 inhibits endometrial cancer cell proliferation by promoting apoptosis through the mitochondrial intrinsic signaling pathway. Biomed Pharmacother 124: 109831, 2020

26. Zheng Y, Wang Q, Li T, Qian J, Lu Y, Li Y, Bi E, Reu F, Qin Y, Drazba J, et al: Role of myeloma-derived MIF in myeloma cell adhesion to bone marrow and chemotherapy response. J Nat Cancer Inst 108: djw131, 2016.

27. Rotow $\mathrm{J}$ and Bivona TG: Understanding and targeting resistance mechanisms in NSCLC. Nat Rev Cancer 17: 637-658, 2017.

28. Hui W, Yan Z, Hui Z and Yu J: Risk factors for bone metastasis in completely resected non-small-cell lung cancer. Future Oncol 13: 695-704, 2017.

29. Yang XY, Liao JJ and Xue WR: FMNL1 down-regulation suppresses bone metastasis through reducing TGF- $\beta 1$ expression in non-small cell lung cancer (NSCLC). Biomed Pharmacother 117: 109126, 2019.

30. Chen L, Zhang YH, Lu G, Huang T and Cai YD: Analysis of cancer-related lncRNAs using gene ontology and KEGG pathways. Artif Intell Med 76: 27-36, 2017.

31. Ding $J$ and Zhang Y: Analysis of key GO terms and KEGG pathways associated with carcinogenic chemicals. Comb Chem High Throughput Screen, Dec 18, 2017 (Online ahead of print).

32. Wang R, Yin C, Fu L, Liu J, Li J and Yin L: Expression profile analysis for epithelial-mesenchymal transition of breast cancer cell line DKTA based on microarray data. Eur J GynaecolOncol 40: 579-584, 2019.

33. Fujita A, Sato JR, Festa F, Gomes LR, Oba-Shinjo SM, Marie SK, Ferreira CE and Sogayar MC: Identification of COL6A1 as a differentially expressed gene in human astrocytomas. Genet Mol Res 7: 371-378, 2008

34. Owusu-Ansah KG, Song G, Chen R, Edoo MIA, Li J, Chen B, Wu J, Zhou L, Xie H, Jiang D and Zheng S: COL6A1 promotes metastasis and predicts poor prognosis in patients with pancreatic cancer. Int J Oncol 55: 391-404, 2019.

35. Zhu YP, Wan FN, Shen YJ, Wang HK, Zhang GM and Ye DW: Reactive stroma component COL6A1 is upregulated in castration-resistant prostate cancer and promotes tumor growth. Oncotarget 6: 14488-14496, 2015.

36. Hou T, Tong C, Kazobinka G, Zhang W, Huang X, Huang Y and Zhang Y: Expression of COL6A1 predicts prognosis in cervical cancer patients. Am J Transl Res 8: 2838-2844, 2016.

37. Wan F, Wang H, Shen Y, Zhang H, Shi G, Zhu Y, Dai B and Ye D: Upregulation of COL6A1 is predictive of poor prognosis in clear cell renal cell carcinoma patients. Oncotarget 6: 27378-27387, 2015 .
38. Frka K, Facchinello N, Del Vecchio C, Carpi A, Curtarello M, Venerando R, Angelin A, Parolin C, Bernardi P, Bonaldo P, et al: Lentiviral-mediated RNAi in vivo silencing of Col6a1, a gene with complex tissue specific expression pattern. J Biotechnol 141: 8-17, 2009.

39. Llacua LA, Hoek A, de Haan BJ and de Vos P: Collagen type VI interaction improves human islet survival in immunoisolating microcapsules for treatment of diabetes. Islets 10: 60-68, 2018.

40. Lamandé SR and Bateman JF: Collagen VI disorders: Insights on form and function in the extracellular matrix and beyond. Matrix Biol 71-72: 348-367, 2018

41. Sato T, Takano R, Tokunaka K, Saiga K, Tomura A, Sugihara H, Hayashi T, Imamura Y and Morita M: Type VI collagen $\alpha 1$ chain polypeptide in non-triple helical form is an alternative gene product of COL6A1. J Biochem 164: 173-181, 2018.

42. Åhrman E, Hallgren O, Malmström L, Hedström U, Malmström A, Bjermer L, Zhou XH, Westergren-Thorsson G and Malmström J: Quantitative proteomic characterization of the lung extracellular matrix in chronic obstructive pulmonary disease and idiopathic pulmonary fibrosis. J Proteomics 189: 23-33, 2018.

43. Xin S, Fang W, Li J, Li D, Wang C, Huang Q, Huang M, Zhuang W, Wang X and Chen L: Impact of STAT1 polymorphisms on crizotinib-induced hepatotoxicity in ALK-positive non-small cell lung cancer patients. J Cancer Res Clin Oncol 147: 725-737, 2021.

44. Blanco MA, LeRoy G, Khan Z, Alečković M,Zee BM, Garcia BA and Kang Y: Global secretome analysis identifies novel mediators of bone metastasis. Cell Res 22: 1339-1355, 2012.

45. Goldstraw P, Chansky K, Crowley J, Rami-Porta R, Asamura H, Eberhardt WE, Nicholson AG, Groome P, Mitchell A, Bolejack V, et al: The IASLC lung cancer staging project: Proposals for revision of the TNM stage groupings in the forthcoming (Eighth) Edition of the TNM classification for lung cancer. J Thorac Oncol 11: 39-51, 2016.

46. Akhurst T: Staging of non-small cell lung cancer. PET Clin 13 $1-10,2018$.

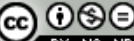

This work is licensed under a Creative Commons

Attribution-NonCommercial-NoDerivatives 4.0 International (CC BY-NC-ND 4.0) License. 